\title{
Proposta de ordenamento das áreas de camping da comunidade da Prainha Branca, Guarujá (SP)
}

\section{Proposal planning of camping areas in the community of Prainha Branca, Guarujá (SP, Brazil)}

\section{Marcos Buhrer Campolim, Ana Paula Garcia, Tathiany Regina Lima Mottola}

\section{RESUMO}

A área de estudo localiza-se na Prainha Branca, município do Guarujá (SP), na Serra do Guararú , local tombado pelo CONDEPHAAT (Resolução SC № 048/1992 - 18/12/1992) devido aos seus atributos naturais e culturais e está inserida na Área de Manejo Especial da Área de Proteção Ambiental Marinha Litoral Centro, Unidade de Conservação do Estado de São Paulo e APA Municipal da Serra do Guararú . Em 2011, iniciaram-se trabalhos conjuntos entre Fundação Florestal e Sociedade Amigos da Prainha Branca, entre outras atividades, visando à regularização das atividades de camping por ser demanda emergencial da comunidade para garantir a renda dos moradores que necessitam desta atividade para subsistência. As atuais áreas de camping apresentam excesso de barracas sem estrutura sanitária adequada para atender o contingente nas áreas de camping. Este trabalho teve como objetivo a formatação de proposta de ordenamento das áreas de campings. Foram coletadas informações junto aos donos das áreas de camping de forma participativa. Os parâmetros considerados foram estrutura sanitária, área disponível e número de pessoas por barraca. Foram analisadas 27 áreas de camping. Priorizou-se a viabilização de áreas de camping para famílias tradicionais residentes. Esta proposta de ordenamento promove redução de $53,3 \%$ da quantidade de barracas, de forma ponderada entre todas as áreas atuais. Espera-se redução dos problemas ambientais da comunidade e melhoria na qualidade dos serviços prestados com melhor rendimento financeiro.

PALAVRAS-CHAVE: Comunidade Tradicional; Prainha Branca; Ordenamento de Camping; Unidade de Conservação.

Página 836 Revista Brasileira de Ecoturismo, São Paulo, v.6, n.5, nov 2013-jan 20I4, pp.836-849. 


\section{ABSTRACT}

The study area is located in Prainha Branca, at Guarujá (SP, Brazil), from Serra do Guararu, this place is protect by government (CONDEPHAAT - Resolução SC $n^{\circ}$ 048/1992 - 12/18/1992) due to its natural and cultural attributes and Special Management Area is embedded in Environmental Protection Area (EPA) of the Central Coast Marine Conservation Unit São Paulo State and Municipality APA Serra do Guararú. In 2011, started joint endeavors between Fundação Florestal and Sociedade Amigos da Prainha Branca, among other activities, aimed at the regularization of camping activities for community emergency demand to ensure the income of the residents who need this activity for subsistence. The current camping areas have excess tents without adequate health structure to meet the quota in camping areas. This work was aimed at planning proposal formatting area campsites. The information was collected with owners of camping areas of the participatory way. The parameters considered were available and sanitary structure, number of people per tent. The 27 camping areas were analyzed. This study prioritized to community traditional families to camping areas residents. This planning proposal promotes reduction of $53.3 \%$ of the quantity of tents, so weighted all areas today. It is expected reduce the environmental problems in the community and improving the quality of services provided with better financial return.

KEYWORKS: Protect Areas; Camping Planning; Prainha Branca; Traditional Community.

\section{Introdução}

A comunidade da Prainha Branca está localizada na Serra do Guararu, município do Guarujá (SP), a qual é uma das últimas porções de dimensões significativas de Mata Atlântica ainda em bom estado de conservação neste município. A orla da praia tem mais de $1,35 \mathrm{~km}$ de areia branca, o que dá origem ao nome. $O$ acesso se dá através de trilha de aproximadamente $2 \mathrm{~km}$ ou por barco (Figura 1).

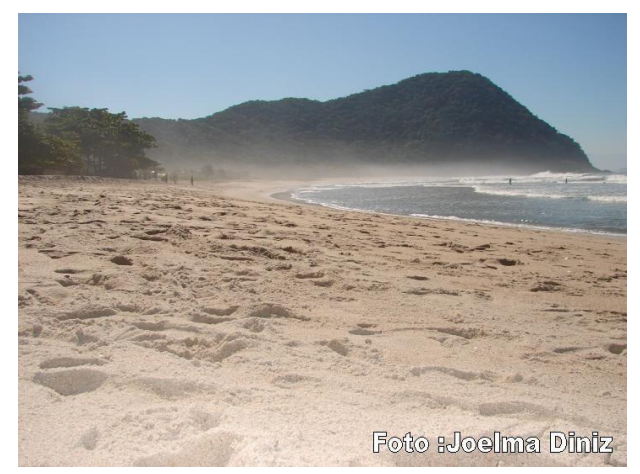

Figura 1: Prainha Branca, Guarujá (SP). Foto: Joelma Diniz.

Figure 1: Prainha Branca, Guarujá (SP, Brazil). Photo: Joelma Diniz. 
Devido à localização geográfica, caracterizada pelos morros que circundam a região, a comunidade da Prainha Branca ficou isolada por várias décadas dos outros habitantes da região. Por isso, os moradores acabaram por desenvolver características culturais diferenciadas. Famílias habitam o local há mais de uma centena de anos e guardam características culturais próprias, além de manter preservada grande parte da vegetação com a qual coexiste.

Atualmente é local de moradia de aproximadamente 100 famílias, o que representa uma população residente de 350 pessoas, podendo a chegar a 4.000 , segundo levantamento realizado pela comunidade, no verão e datas festivas. Reúne construções típicas da cultura caiçara e mantém característica rural, sem acessos por vias públicas e infraestrutura. A característica caiçara na comunidade da Prainha Branca subsiste na forma de se expressar, no vestuário e, sobretudo no autoreconhecimento desta identidade (PETROBRAS, 2012).

Segundo laudo antropológico (TURATTI, 2012) e depoimento dos moradores locais (PETROBRAS, 2012), mais de $84 \%$ das ocupações são de famílias que tradicionalmente ocupam esta área.

Os moradores tradicionais viviam a base da atividade rural, extrativismo e a pesca; estas ainda ocorrem, porém a principal fonte de renda hoje existente na comunidade é a atividade turística, a qual se enquadra dentro dos conceitos de turismo de base comunitária, evidenciada pela estrutura do comércio, através de lojas de artesanato, bares, pequenos restaurantes, pousadas e campings (TURATTI, 2012). Atualmente existem 11 pousadas, 25 áreas de camping e 16 comércios (PETROBRAS, 2012).

Nesta comunidade existe a Sociedade Amigos da Prainha Branca (SAPB), fundada em 1972, com o intuito de representar a mesma e gerenciar questões de lixo, segurança, educação e turismo sustentável de maneira que minimize os impactos no local.

O Conselho de Defesa do Patrimônio Histórico, Arqueológico, Artístico e Turístico do Estado de São Paulo - CONDEPHAAT, promoveu o Tombamento da Serra do Guararu, incluindo Prainha Branca - Guarujá por meio da Resolução SC № 048/1992 - 18/12/1992 (SÃO PAULO, 1992). Esta Resolução considerou que a Vila da Prainha Branca, apesar das transformações ocorridas em sua estrutura econômica, ainda guarda alguns elementos culturais típicos de comunidades isoladas de pescadores, dentre os quais se destaca a própria paisagem local, enquanto forma de apropriação do espaço, onde predominam o respeito e a integração dos elementos naturais.

A Área de Proteção Ambiental Marinha Litoral Centro (APAMLC), Unidade de Conservação da categoria de Uso Sustentável (BRASIL, 2000) gerenciada pela Fundação Florestal, Secretaria de Estado do Meio Ambiente, foi criada pelo Decreto $n^{\circ}$ 53.526, de 8 de outubro de 2008 (SÃO PAULO, 2008), com a finalidade de proteger, ordenar, garantir e disciplinar o uso racional dos recursos ambientais da 
região, inclusive suas águas, bem como ordenar o turismo recreativo, as atividades de pesquisa e pesca e promover o desenvolvimento sustentável da região.

Na APAMLC, a região denominada Ponta da Armação engloba toda a comunidade da Prainha Branca, e é considerada Área de Manejo Especial (AME) desta Unidade de Conservação, cuja finalidade é a proteção da biodiversidade, o combate a atividades predatórias, o controle da poluição e a sustentação da produtividade pesqueira (SÃO PAULO, op.cit.).

A AME Ponta da Armação está devidamente delimitada no Decreto de criação da APAMLC e possui áreas terrestres e marinhas perfazendo um perímetro de 15.343 metros e área de 1.405,301 ha (SÃO PAULO, op.cit.) (Figura 2).
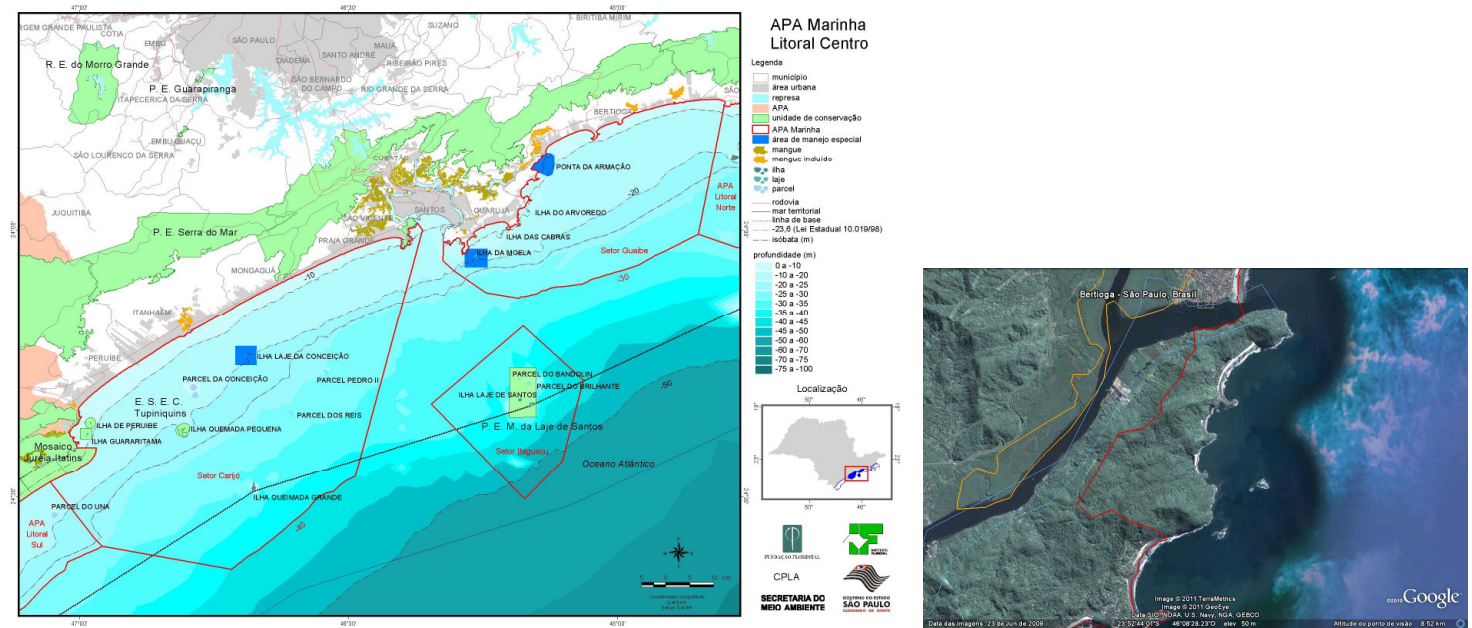

Figura 2: Mapa da APA Marinha Litoral Centro e detalhe com mapa da Área de Manejo Especial Ponta da Armação. Fonte: Fundação Florestal (2008).

Figure 2: Map of the APA Marinha Litoral Centro and detail map of the Área de Manejo Especial Ponta da Armação. Source: Fundação Florestal (2008).

Recentemente o município do Guarujá criou a APA da Serra do Guararu (GUARUJÁ, 2012) qual sobrepõe à APAMLC e proporciona à Prainha Branca mais um reconhecimento legal de conservação.

Na Prainha Branca, até meados da década de 90, os turistas que visitavam o local praticavam o chamado "camping selvagem", caracterizado pela colocação das barracas na praia e floresta. Nesta época, os campistas não contavam com infraestrutura mínima como água e banheiro (SIMÕES; KAMYIAMA, 2003).

Muitos moradores da Prainha Branca identificaram a atividade de camping em suas propriedades como fonte de obtenção de renda, sendo que para algumas famílias trata-se de renda complementar e para outras a principal. Tais moradores iniciaram a implantação de infraestrutura para receber os turistas, porém sem 
orientação adequada quanto aos parâmetros aceitáveis com relação à capacidade de suporte dos campings, resultando em excesso de barracas sem estrutura sanitária adequada para atender o contingente nas áreas de camping e a disseminação de uma cultura do retorno financeiro pela quantidade e não pela qualidade. Problemas sociais na comunidade como uso ilícito de drogas, pequenos furtos e outros incômodos sociais diversos, foram intensificados.

Em 1978, trabalhos no comércio local representavam $11 \%$ da ocupação da população economicamente ativa da Prainha Branca. Atualmente representa $23 \%$. Nota-se que há um crescimento das atividades relativas ao comércio local. A explicação para tal fenômeno reside no fato de que, a partir dos anos 1970, acampar na Prainha Branca "virou moda", já que o acesso havia sido facilitado pela abertura das Rodovias Ariovaldo de Almeida Viana e Padre Manuel da Nóbrega. Os campistas instalavam-se na areia e demandavam serviços de alimentação, o que incentivou o surgimento de mais bares/restaurantes (PETROBRAS, 2012).

Em 1999 a Promotoria de Justiça do Meio Ambiente do Guarujá protocolou o Termo de Ajustamento de Conduta (TAC) n. 13/97 - MA, o qual versa sobre a deficiência na prestação de serviço público essencial de coleta de lixo na Prainha Branca, além da degradação ambiental decorrente da poluição acarretada pela omissão do Poder Executivo municipal (SÃO PAULO, 1999). No termo 1 do referido TAC, determinou-se que: "não permitirá, patrocinará, ou, de qualquer modo, autorizará a realização de atividades de camping na Prainha Branca, bem como de qualquer atividade potencialmente degradadora do meio ambiente". O termo 2 aborda que "intensificará a fiscalização na Prainha Branca, para coibir qualquer tipo de atividade potencialmente degradadora do meio ambiente, além do camping".

Através deste TAC, a atividade de camping na Prainha Branca foi proibida. Tal medida prejudicou os moradores cuja subsistência provinha desta atividade.

Para tentar sanar tal problema, em 2006 foi criada a Associação Caiçara de Camping da Prainha Branca, a qual formatou a primeira proposta de ordenamento de áreas de camping. Apesar do esforço da comunidade na elaboração da referida proposta, esta não teve êxito junto ao Ministério Público.

Em virtude de a Prainha Branca ser Área de Manejo Especial da APAMLC, em 2011 iniciaram-se trabalhos conjuntos entre a Fundação Florestal e a Sociedade Amigos da Prainha Branca, visando contribuir para o ordenamento das atividades de visitação pública da área. A regularização das atividades de camping foi demanda emergencial para garantir a renda dos moradores que necessitam desta atividade para subsistência.

Neste contexto, o trabalho tem como objetivo descrever a formatação de proposta de ordenamento das áreas de campings, de forma participativa com a comunidade tradicional da Prainha Branca, a qual visa regularizar esta atividade, minimizar degradação ambiental e contribuir para as atividades de turismo de base comunitária. 


\section{Materiais e métodos}

Atendendo conceitos de turismo sustentável e de base comunitária e utilizando ferramentas de planejamento e gestão participativa (MITRAUD, 2004; MEDINA, 2005), utilizou-se metodologia participativa com os donos das áreas de camping da Prainha Branca para a elaboração da proposta de ordenamento. Realizou-se o diagnóstico do problema, através da análise histórica da atividade de camping, aplicaram-se parâmetros técnicos para a definição das cotas de barracas e reuniões formais de validação da proposta com os donos das áreas de camping. Tal metodologia foi embasada na proposta de ordenamento de campings da comunidade tradicional do Marujá, inserida no Parque Estadual Ilha do Cardoso (PEIC) (CAMPOLIM, et al., 2008). O produto da proposta metodológica aplicada na comunidade do Marujá foi formalizado no Plano de Manejo do PEIC (SÃO PAULO, 2001).

A participação social em metodologias de análise da efetividade do manejo de áreas protegidas baseia-se em entender os problemas atuais do local e orientá-los a atingir o objetivo de conservação. A legitimidade social ocorre quando os atores reconhecem, apropriam e incorporam no desenvolvimento de suas vidas os objetivos de conservação, a existência da área protegida e a função pública de conservação exercida pelas autoridades competentes (MEDINA, 2005).

O levantamento dos dados dos campings foi realizado através do preenchimento de planilhas por uma comissão de donos de camping e monitores ambientais da APAMLC. Todas as áreas de camping foram visitadas e os donos de camping foram entrevistados para coletar informações sobre área disponível $\left(\mathrm{m}^{2}\right)$ para acomodação das barracas, infraestrutura receptiva (quantidade de barracas e quantidade de quartos), infraestrutura de saneamento (quantidade de banheiros para o camping, existência de fossa e quantidade de chuveiros), questões relacionadas ao lixo e a forma de abastecimento de água.

Além das visitas aos campings, foram realizadas quatro assembleias com os donos dos campings onde foram discutidos os diagnósticos das áreas, estabelecidos os parâmetros de análise e a formatação da proposta de ordenamento: 24 de outubro, 04 e 09 de novembro de 2011 e 12 de dezembro de 2011. Todos os encaminhamentos foram registrados em atas das assembleias e os participantes em lista de presença, documentos estes que integram a proposta de ordenamento formatada a exemplo do processo desenvolvido na comunidade do Marujá (CAMPOLIM, et al., 2008).

A definição dos parâmetros utilizados para estabelecer as cotas de barracas por camping foi:

- Estrutura sanitária: 1 banheiro comporta até 20 pessoas;

- Área disponível: 1 barraca ocupa uma área mínima de $15 \mathrm{~m}^{2}$;

- Número de pessoas por barraca: 1 barraca comporta até 3 pessoas. Normalmente acomoda 2 pessoas. 
Os três parâmetros definidos foram utilizados em conjunto na análise para definição de todas as áreas de camping. Para estabelecer a quantidade de barracas, foi utilizado o parâmetro que proporcionou a menor quantidade de barracas por área de camping.

A Tabela 1 resume as relações entre os parâmetros utilizados quanto à quantidade de banheiros:

Tabela 1: Parâmetros para quantificação de número de barracas.

Table 1: Parameters for quantifying the number of tents.

\begin{tabular}{|c|c|c|}
\hline Quantidade de banheiros & $\begin{array}{c}\text { Quantidade de } \\
\text { Pessoas }\end{array}$ & Quantidade de barracas \\
\hline 1 & 20 & 13 \\
\hline 2 & 40 & 20 \\
\hline 3 & 60 & 26 \\
\hline 4 & 80 & 33 \\
\hline 5 & 100 & 40 \\
\hline 6 & 120 & 46 \\
\hline 7 & 140 & \\
\hline
\end{tabular}

Fonte: Autores. Source: Authors.

Na relação estrutura sanitária e número de pessoas por barracas, utilizou-se o arredondamento do cálculo para menor, visando à qualidade ambiental.

\section{Resultados e discussão}

Frente deficiência de estudos de capacidade de suporte de áreas de camping dentro de conceitos de turismo de base comunitária, o estudo desenvolvido na comunidade do Marujá - PEIC (CAMPOLIM, et. al., 2008) fundamentou a presente proposta. O envolvimento da comunidade local se deu por meio de vistorias em cada área de camping por comissão designada e participação do responsável pela área e por assembleias com todos os donos de camping que se enquadram como moradores tradicionais onde foram discutidos diagnósticos e parâmetros de análises e definição de cotas de cada área de camping.

Os parâmetros considerados sempre foram os mais restritivos, ou seja, visando a menor quantidade de barracas por área de camping, de modo a garantir melhora da 
qualidade ambiental.

Em quatro áreas de camping, os proprietários fizeram a opção espontânea de reduzir o número de barracas os quais teriam direito segundo os parâmetros préestabelecidos. Para estas áreas, se os parâmetros fossem aplicados, comportariam um total de 72 barracas. Com a opção de redução espontânea, o total destas quatro áreas foi de 49, ocorrendo redução espontânea de 23 barracas do total geral.

A seguinte análise foi realizada por área de camping:

1. Camping da Mara: Ocupante tradicional. O parâmetro limitante para definição da quantidade de barracas neste camping foi à quantidade de banheiros;

2. Fribscamping: Ocupante tradicional. O parâmetro limitante para definição da quantidade de barracas neste camping foi à quantidade de banheiros;

3. Camping da Árvore: Ocupante tradicional. O parâmetro limitante para definição da quantidade de barracas neste camping foi à quantidade de banheiros;

4. Camping Guarú: Ocupante tradicional. O parâmetro limitante para definição da quantidade de barracas neste camping foi à quantidade de banheiros;

5. Camping da Ludnéia: Ocupante tradicional. O parâmetro limitante para definição da quantidade de barracas neste camping foi à quantidade de banheiros;

6. Camping da Lúcia: Ocupante tradicional. O parâmetro limitante para definição da quantidade de barracas neste camping foi à área disponível;

7. Camping Maria Branca: Ocupante tradicional. Apesar dos parâmetros limitantes permitirem maior número de barracas, a opção do proprietário foi estabelecer a quota de 10 barracas;

8. Recanto da llha: Ocupante tradicional. O parâmetro limitante para definição da quantidade de barracas neste camping foi à área disponível;

9. Camping do Pássaro: Ocupante tradicional. O parâmetro limitante para definição da quantidade de barracas neste camping foi à quantidade de banheiros;

10. Camping São José: Ocupante tradicional. $O$ parâmetro limitante para definição da quantidade de barracas neste camping foi à quantidade de banheiros;

11. Recanto do Lago: Ocupante tradicional. O parâmetro limitante para definição da quantidade de barracas neste camping foi à quantidade de banheiros;

12. Camping do Cantão: Ocupante tradicional. O parâmetro limitante para 
definição da quantidade de barracas neste camping foi à quantidade de banheiros;

13. Camping Ari e Célia: Ocupante tradicional. O parâmetro limitante para definição da quantidade de barracas neste camping foi à quantidade de banheiros;

14. Camping do Felipe: Ocupante tradicional. O parâmetro limitante para definição da quantidade de barracas neste camping foi à área disponível;

15. Camping Prainha Branca: Ocupante tradicional. O parâmetro limitante para definição da quantidade de barracas neste camping foi à área disponível;

16. Camping da Dionéia: Ocupante tradicional. Apesar dos parâmetros limitantes permitirem maior número de barracas, a opção da proprietária foi estabelecer a quota de 15 barracas;

17. Camping da Cici: Ocupante tradicional. Apesar dos parâmetros limitantes permitirem maior número de barracas, a opção da proprietária foi estabelecer a quota de 20 barracas;

18. Camping 3 irmãos: Ocupante tradicional. O parâmetro limitante para definição da quantidade de barracas neste camping foi à quantidade de banheiros;

19. Camping da Marina: Ocupante tradicional. O parâmetro limitante para definição da quantidade de barracas neste camping foi à quantidade de banheiros;

20. Camping da Florência: Ocupante tradicional. O parâmetro limitante para definição da quantidade de barracas neste camping foi à quantidade de banheiros;

21. Camping da Lica: Ocupante tradicional não residente. O parâmetro limitante para definição da quantidade de barracas neste camping foi à quantidade de banheiros;

22. Camping da Isaura: Ocupante tradicional não residente. O parâmetro limitante para definição da quantidade de barracas neste camping foi à quantidade de banheiros;

23. Camping da Dulce: Ocupante tradicional não residente. O parâmetro limitante para definição da quantidade de barracas neste camping foi à quantidade de banheiros;

24. Camping da Vera Lúcia: Ocupante tradicional não residente. O parâmetro limitante para definição da quantidade de barracas neste camping foi à quantidade de banheiros;

25. Camping do Cristiano: Ocupante não tradicional com família residente ininterruptamente na comunidade e que tem nas atividades de camping e 
monitoria ambiental suas principais fontes de renda familiar, além de realizar voluntariamente trabalhos comunitários na área social e ambiental nesta comunidade. Em Assembléia, foi consenso entre todos a permanência da atividade de seu camping;

26. Camping Toca da Garoupa: Ocupante tradicional residente. Esta área de camping está localizada na Ponta da Armação, local com acesso pela trilha que se destina a Prainha Branca. O parâmetro limitante para definição da quantidade de barracas neste camping foi à quantidade de banheiros;

27. Camping Tabajara: Ocupante não tradicional e não residente. Em Assembléia, foi consenso entre todos que esta área de camping não deve continuar em atividade.

A Proposta de Ordenamento das Áreas de Camping da Prainha Branca estipula quota máxima de barracas por área de camping segundo a Tabela 2 (página seguinte):

A quantidade atual de barracas nos campings da Prainha Branca identificada no diagnóstico foi de 1147. Com a proposta de ordenamento emergencial apresentada, chegou-se a 536 barracas (Tabela 2), representando uma redução de $53,3 \%$ da quantidade de barracas.

O estabelecimento de número máximo de pessoas por equipamento sanitário objetiva melhoria da qualidade ambiental. Na Prainha Branca o esgoto não é coletado pelo poder público, e a população deposita seus efluentes em fossas sépticas. No geral, em relação ao saneamento básico, o esgotamento sanitário é o que mais assola a comunidade, principalmente na alta temporada, quando a demanda aumenta (PETROBRAS, 2012).

No estudo realizado na comunidade do Marujá (CAMPOLIM, et al, 2008) a proposta inicial foi 0 estabelecimento de 15 barracas por banheiro. Com 0 monitoramento realizado pela administração do PEIC, verificou-se a necessidade de readequação desta cota, chegando-se em 6 barracas por banheiro. A proposta de ordenamento das áreas de camping da Prainha Branca coincide com a proposta estabelecida na comunidade do Marujá - PEIC quanto ao número de barracas por banheiro.

A comunidade do Marujá - PEIC apresentava condições mais precárias do que as existentes hoje na Prainha Branca e desenvolveu sistema de ordenamento de camping de forma participativa o que contribuiu para a consolidação do turismo de base comunitária (CAMPOLIM, et al, 2008). O efetivo controle da quantidade de turistas é realizado por meio de reservas antecipadas e contagem de barracas e de leitos ocupados em pousadas pelos próprios moradores.

O estudo de Campos relatou que o número limite de visitantes no Marujá PEIC foi estabelecido pela quantidade máxima de barracas a qual é calculada de

Página 845 Revista Brasileira de Ecoturismo, São Paulo, v.6, n.5, nov 20।3-jan 20I4, pp.836-849. 
acordo com o número de banheiros, assim como a presente proposta. Tal medida tem se mostrado eficaz para o controle da quantidade de visitantes e da garantia da qualidade ambiental.

Tabela 2: Proposta de número de barracas/camping.

Table 2: Proposed number of tents/camping.

\begin{tabular}{|c|c|c|}
\hline Id & NOME & $\begin{array}{c}\text { Proposta para cada camping } \\
\text { (barracas) }\end{array}$ \\
\hline 1 & Camping da Mara & 26 \\
\hline 2 & Fribscamping & 13 \\
\hline 3 & Camping da Árvore & 13 \\
\hline 4 & Camping Guarú & 20 \\
\hline 5 & Camping da Ludnéia & 13 \\
\hline 6 & Camping da Lucia & 8 \\
\hline 7 & Camping Maria Branca & 10 \\
\hline 8 & Recanto da Ilha & 17 \\
\hline 9 & Camping do Pássaro & 33 \\
\hline 10 & Camping São José & 33 \\
\hline 11 & Recanto do Lago & 40 \\
\hline 12 & Camping do Cantão & 26 \\
\hline 13 & Camping Ari e Célia & 46 \\
\hline 14 & Camping do Felipe & 4 \\
\hline 15 & Camping Prainha Branca & 15 \\
\hline 16 & Camping da Dionéia & 15 \\
\hline 17 & Camping da Cici & 20 \\
\hline 18 & Camping 3 Irmãos & 20 \\
\hline 19 & Camping da Marina & 26 \\
\hline 20 & Camping da Florência & 26 \\
\hline 21 & Camping da Lica & 20 \\
\hline 22 & Camping da Isaura & 26 \\
\hline 23 & Camping da Dulce & 20 \\
\hline 24 & Camping da Vera Lúcia & 20 \\
\hline 25 & Camping do Cristiano & 13 \\
\hline \multirow[t]{2}{*}{26} & Camping Toca da Garoupa & 13 \\
\hline & TOTAL & 536 \\
\hline
\end{tabular}

Fonte: Autores. Source: Authors. 
A proposta de ordenamento de camping da Prainha Branca priorizou a viabilização de áreas de camping para famílias tradicionais residentes, visto ter um TAC do Ministério Público que proíbe a atividade. A ocorrência destas famílias tradicionais é identificada em Laudo Antropológico (TURATTI, 2012) e existe o reconhecimento como comunidade tradicional pelo tombamento do CONDEPHAAT. O Decreto № 6.040 de 2007 institui a Política Nacional de Desenvolvimento Sustentável dos Povos e Comunidades Tradicionais (BRASIL, 2007) e define o conceito de população tradicional como grupos culturalmente diferenciados e que se reconhecem como tais, que possuem formas próprias de organização social, que ocupam e usam territórios e recursos naturais como condição para sua reprodução cultural, social, religiosa, ancestral e econômica, utilizando conhecimentos, inovações e práticas gerados e transmitidos pela tradição.

No caso de ocupantes não tradicionais, foram detectadas duas situações: uma quando o ocupante é não tradicional residente e outra quando é não tradicional não residente. $\mathrm{O}$ dono de camping não tradicional residente foi inserido nesta proposta, por morar na Prainha Branca há muito tempo e por realizar atividades benéficas ao local, como por exemplo, exercer a função de Monitor Ambiental local. Tal fato não ocorreu para o dono de camping não tradicional não residente. Esta decisão foi consenso em Assembleia.

O turismo comunitário é uma estratégia para que populações tradicionais, independente do grau de descaracterização frente à hegemonia das sociedades urbanas industriais, sejam protagonistas de seus modos de vida próprios, tornando-se uma alternativa possível ao modo de vida materialista-consumista (SAMPAIO, 2008).

Atrelado ao ordenamento de áreas de camping outras atividades estão sendo realizadas, como capacitação dos monitores ambientais locais, fomento às atividades de estudo do meio por grupos escolares com pernoites na comunidade, capacitação dos prestadores de serviço de transporte náutico (barqueiros), estudos de tratamento de esgoto adaptado às condições locais, entre outros.

$O$ estudo "O turismo de base comunitária no Parque Estadual da llha do Cardoso" o qual relata as intervenções para a consolidação do ordenamento de camping na comunidade do Marujá - PEIC (SANTA RITA et al., 2002) recebeu o Prêmio SESC-SENAC de Turismo Sustentável, em dezembro de 2002, como forma de reconhecimento da importância do trabalho para a melhoria da qualidade de vida da comunidade e da qualidade ambiental. Houve ainda a mudança do perfil do visitante nessa comunidade (aumento da procura por pesquisadores, empresários, grupos organizados de estudantes e famílias), sendo também um importante indicativo da consolidação desse processo.

\section{Conclusões}

A metodologia utilizada com a participação efetiva dos atores envolvidos no diagnóstico, planejamento e validação da proposta, apresentou-se eficiente do ponto 
de vista ambiental pela redução significativa do número de barracas e do ponto de vista social em decorrência da valorização dos ocupantes tradicionais e pela aplicação do conceito da melhor socialização dos recursos oriundos da exploração turística, pois houveram reduções ponderadas de barracas por cada área de camping.

A experiência em andamento na Prainha Branca apresenta boa viabilidade de consolidação do turismo de base comunitária, a exemplo do ocorrido na comunidade do Marujá - PEIC, referência em turismo de base comunitária.

Espera-se redução dos problemas ambientais da comunidade da Prainha Branca, melhoria na qualidade dos serviços prestados, melhor rendimento financeiro e mudança cultural quanto à gestão das áreas de camping, visando à qualidade do receptivo em detrimento da quantidade de barracas.

Efetivada a formalização e implementação desta proposta, propõe-se a revisão da mesma baseada no monitoramento continuado de modo a adequar melhorias ambientais e sociais, atendendo aos princípios de turismo de base comunitária.

\section{Referências bibliográficas}

BRASIL. Decreto no 6.040, de 7 de fevereiro de 2007. Institui a Política Nacional de Desenvolvimento Sustentável dos Povos e Comunidades Tradicionais, 2007.

BRASIL. Ministério do Meio Ambiente. Sistema Nacional de Unidades de Conservação - SNUC: lei no 9.985 de 18 de julho de 2000 e decreto no 4.340, de 22 de agosto de 2002. 4. ed. Brasília, DF, 2004. 52 p.

CAMPOLIM, M.B., PARADA, I.L.S., YAMAOKA, J.G. Gestão Participativa da Visitação Pública na comunidade do Marujá - Parque Estadual da llha do Cardoso. IF Sér. Reg., São Paulo, n. 33, p. 39-49, 2008.

CAMPOS, L.P. Preservação ambiental e ecoturismo na comunidade do Marujá, Ilha do Cardoso-SP. Departamento de Geografia/IGC - Universidade Federal de Minas Gerais. 6p, s/d.

GUARUJÁ. Decreto Municipal no 9.948, de 28 de junho de 2012. Cria a Área de Proteção Ambiental Minucipal da Serra do Guararu e dá outras providências, 2012.

MEDINA, M.M. (Org.). Análisis de efectividad del manejo de áreas protegidas con participación social. Contexto y marco conceptual. Cali: Editorial WWF Colombia. 64 p. 2005

MITRAUD, S. (Org.). Manual de ecoturismo de base comunitária: ferramentas para um planejamento responsável. Brasília, DF: WWF-Brasil, 164 p. 2004

PETROBRAS. Estudo Socioambiental Ponta da Armação, Guarujá/SP. Relatório Técnico Executivo - Diagnóstico Socioeconômico. v. único, 114p, 2012.

SAMPAIO, C.A.C.; ALVES, F.K.; FALK, V.C.V. Arranjo socioprodutivo de base comunitária: interconectando o turismo comunitário com redes de comércio justo. Revista Turismo Visão e Ação - Eletrônica, v. 10, no 02, p. 244 - 262, 2008. 
SANTA RITA, B.S.; PARADA, I.L.S.; CAMPOLIM, M.B. O turismo de base comunitária no Parque Estadual da llha do Cardoso. Prêmio Sesc/Senac de Turismo Sustentável estudo de caso. São Paulo, 15p. 2002. (não publicado).

SÃO PAULO. Ministério Público do Estado. Termo de Compromisso de Ajustamento de Conduta 13/97 - MA, 1999.

SÃO PAULO. Estado. Resolução SC № 048/1992 de 18 de dezembro de 1992. Dispõe sobre o tombamento da Serra do Guararu, incluindo Prainha Branca - Guarujá. 1992

SÃO PAULO. Decreto Estadual $\mathbf{n}^{\circ} \mathbf{5 3 . 5 2 6}$ de 8 de outubro de 2008. Dispõe sobre a criação da Área de Proteção Ambiental Marinha Litoral Centro, e da providências correlatas. 2008.

SÃo PAULO. Estado. Secretaria do Meio Ambiente. Plano de Manejo do Parque Estadual da Ilha do Cardoso. São Paulo. 196 p. 2001 (relatório não publicado).

SIMÕES, L.L.; KAMYIAMA, H. Avaliação dos impactos do turismo na Prainha Branca, Guarujá/SP. Relatório Técnico. 15p, 2003.

TURATTI, M. C. M. Estudo Socioambiental Ponta da Armação, Guarujá/SP - Laudo Antropológico. 399p, 2012.

Marcos Buhrer Campolim: Fundação Florestal, São Paulo, SP, Brasil.

Email: marcoscampolim@yahoo.com.br

Link para o currículo Lattes: http://lattes.cnpq.br/6754842144588794

Ana Paula Garcia: Fundação Florestal, São Paulo, SP, Brasil.

Email: anagarcia.bio@gmail.com

Link para o currículo Lattes: http://lattes.cnpq.br/1292686282354718

Tathiany Regina Lima Mottola: Fundação Florestal, São Paulo, SP, Brasil.

Email: tathianyl@yahoo.com.br

Link para o currículo Lattes: http://lattes.cnpq.br/0507970704818097

Data de submissão: 31 de maio de 2012

Data de recebimento de correções: 16 de julho de 2013

Data do aceite: 20 de setembro de 2013

Avaliado anonimamente 